\title{
Operationalizing an integrative socio-ecological framework in support of global monitoring of land degradation
}

\author{
Narcisa Pricope ${ }^{1}$, Gabriel Daldegan ${ }^{2}$, Alex Zvoleff ${ }^{2}$, Kevin Mwenda ${ }^{3}$, Monica Noon ${ }^{2}$, and \\ David Lopez-Carr ${ }^{4}$ \\ ${ }^{1}$ University of North Carolina at Wilmington College of Arts and Sciences \\ ${ }^{2}$ Conservation International \\ ${ }^{3}$ Brown University \\ ${ }^{4}$ University of California Santa Barbara
}

February 21, 2022

\begin{abstract}
Despite sustained global efforts to avoid, reduce, and reverse land degradation, estimates of land degradation nationally and regionally vary considerably. Land degradation reduces agricultural productivity, impacts the provision of vital ecosystem services, and disproportionately affects vulnerable populations. The 2030 Agenda for Sustainable Development, through Sustainable Development Goal (SDG) 15.3, sets out to achieve land degradation neutrality (LDN) by improving the livelihoods of those most affected and building resilience in areas affected by or at risk from degradation. The United Nations Convention to Combat Desertification (UNCCD) leads the charge in creating a spatially-explicit framework for monitoring and reporting on LDN goals that countries can integrate into their land planning policies. However, it remains difficult to operationalize the integration of biophysical indicators of land degradation with climatic and socio-economic indicators to assess the impact of land degradation on vulnerable populations. We present an integrative framework that demonstrates how freely available global geospatial datasets can be leveraged through an open-source platform (Trends.Earth) to simplify and operationalize monitoring and reporting on progress towards achieving LDN. Then, we summarize a suite of datasets and approaches that can be used to understand and quantify the socio-ecological interactions between drought, land degradation and population exposed to desertification, land degradation and drought (DLDD). We discuss how improvements in Earth Observation (EO) datasets and algorithms will allow UNCCD land-based progress sub-indicators (changes in primary productivity, land cover, soil organic carbon, drought, and population exposure) to be computed at enhanced spatial resolutions.
\end{abstract}

\section{Hosted file}

LDD Special Issue Paper v1 Final.docx available at https://authorea.com/users/461656/ articles/557292-operationalizing-an-integrative-socio-ecological-framework-in-supportof-global-monitoring-of-land-degradation 